\section{BMJ Open Respiratory Research}

\title{
Complications and discomfort after research bronchoscopy in the MicroCOPD study
}

Elise Orvedal Leiten (D) , ${ }^{1}$ Tomas Mikal Lind Eagan, ${ }^{1,2}$ Einar Marius Hjellestad Martinsen, ${ }^{1}$ Eli Nordeide, ${ }^{2}$ Gunnar Reksten Husebø, ${ }^{1,2}$ Kristel Svalland Knudsen, ${ }^{2}$ Sverre Lehmann, ${ }^{1,2}$ Øistein Svanes, ${ }^{1,2}$ Per Sigvald Bakke, ${ }^{1}$ Rune Nielsen ${ }^{1,2}$

To cite: Leiten EO, Eagan TML, Martinsen EMH, et al. Complications and discomfort after research bronchoscopy in the MicroCOPD study. BMJ Open Resp Res 2020;7:e000449. doi:10.1136/ bmjresp-2019-000449

- Additional material is published online only. To view please visit the journal online (http://dx.doi.org/10.1136/ bmjresp-2019-000449).

An early version of this work was presented in poster form September 12th 2017 at the European Respiratory Society International Congress in Milan.

Received 22 May 2019 Revised 7 January 2020 Accepted 27 January 2020

Check for updates

(C) Author(s) (or their employer(s)) 2020. Re-use permitted under CC BY-NC. No commercial re-use. See rights and permissions. Published by BMJ.

${ }^{1}$ Department of Clinical Science, University of Bergen, Bergen, Norway

${ }^{2}$ Department of Thoracic Medicine, Haukeland University Hospital, Bergen, Norway

Correspondence to Dr Elise Orvedal Leiten; elise.leiten@uib.no

\section{ABSTRACT}

Background Data on discomfort and complications from research bronchoscopy in chronic obstructive pulmonary disease (COPD) and asthma is limited. We present complications and discomfort occurring within a week after bronchoscopy, and investigate personal and procedural risk factors.

Methods 239 subjects with COPD, asthma or without lung disease underwent research bronchoscopies as part of a microbiome study of the lower airways (the MicroCOPD study). Bronchoscopy was done in the supine position with oral scope insertion with the option of light conscious alfentanil sedation. Sampling consisted of protected specimen brushes, bronchoalveolar lavage, small volume lavage and for some, endobronchial biopsies. Bleeding, desaturation, cough, haemodynamic changes, dyspnoea and other events that required an unplanned intervention or early termination of bronchoscopy were prospectively recorded. Follow-up consisted of a telephone interview where subjects rated discomfort and answered questions about fever sensation and respiratory symptoms in the week following bronchoscopy.

Results An unplanned intervention or early termination of bronchoscopy was required in $25.9 \%$ of bronchoscopies. Three subjects (1.3\%) experienced potentially severe complications, of which all recovered without sequelae. COPD subjects experienced more dyspnoea than controls. Sedation and lower age was associated with less unplanned intervention or premature termination. About half of the subjects $(47.7 \%)$ reported fever. Discomfort was associated with postprocedural fever, dread of bronchoscopy, higher score on the COPD Assessment Test and never-smoking. In subjects undergoing more than one bronchoscopy, the first bronchoscopy was often predictive for complications and postprocedural fever in the repeated bronchoscopy.

Conclusion Research bronchoscopies were not associated with more complications or discomfort in COPD subjects. $47.7 \%$ experienced postbronchoscopy fever sensation, which was associated with discomfort.

\section{INTRODUCTION}

Bronchoscopy is a standard diagnostic procedure in lung cancer and interstitial lung disease. In addition, many patients with obstructive lung disease undergo bronchoscopy as part of differential diagnostics or for microbial sampling.

The reported complication rates of bronchoscopy vary considerably. For instance bleeding varies from $2.5 \%$ to $100 \%$ of procedures $^{12}$ and desaturation from $0.7 \%$ to $76.3 \%$ of procedures. ${ }^{34}$ Fever, perhaps more of a discomfort than a complication, occurs in $2 \%-33 \%$ of bronchoscopies. ${ }^{56}$ This variation in reported rates can be attributed to a lack of sufficiently powered studies with clearly defined outcomes, and to a heterogeneity in study populations and local practices. The paucity of information about specific procedure-related and patient-related factors, also applies to bronchoscopy in highprevalent illnesses such as chronic obstructive pulmonary disease (COPD). ${ }^{7}$ Accurate knowledge would serve to better prepare patients and prime bronchoscopists' awareness of possible discomforts and complications for patients undergoing bronchoscopy.

In the Bergen COPD microbiome study (MicroCOPD) ${ }^{8}$ we performed more than 300 research bronchoscopies in subjects with and without obstructive pulmonary disease. The current analysis investigates if research bronchoscopy is less safe in subjects with obstructive lung disease by evaluating complications and discomfort occurring immediately, and within a week after bronchoscopy.

\section{MATERIALS AND METHODS}

\section{Study population}

The MicroCOPD study included COPD and asthma patients as well as subjects without lung or airways disease ('controls'). ${ }^{8}$ Participants were recruited from the Bergen COPD Cohort Study ${ }^{9}$ and the GenKOLS Study, ${ }^{10}$ in addition to volunteers from the outpatient clinic at the Department of Thoracic 
Medicine, Haukeland University Hospital and asthma patients from a local pulmonology clinic. COPD and control subjects were 40 years or older. The COPD and asthma diagnoses were verified by experienced pulmonologists based on spirometry (COPD: postbronchodilation forced expiratory volume in 1 second/forced vital capacity $\left(\mathrm{FEV}_{1} / \mathrm{FVC}\right)<0.7$, according to Global Initiative for Chronic Obstructive Lung Disease (GOLD) guidelines ${ }^{11}$ ), respiratory symptoms, disease history and other diagnostic modalities such as CT of the lungs. No bronchoprovocation challenge was conducted. Control subjects were subjects that did not have symptoms or lung function tests compatible with a diagnosis of airways disease. A pilot study was conducted with eight COPD subjects before starting the main study, as part of protocol development. All participants provided written informed consent prior to inclusion.

\section{Selection for bronchoscopy}

Participation was postponed in subjects that had been treated for a COPD exacerbation within the last 2 weeks, or who had ongoing respiratory symptoms. Bronchoscopy was not performed in subjects that were hypoxemic despite oxygen supplementation $\left(\mathrm{O}_{2}\right.$ saturation $\left.<90 \%\right)$, hypercapnic, at increased risk of bleeding, had known allergy towards the premedication, or had cardiac risk factors as specified in the protocol. ${ }^{8}$

\section{Bronchoscopy procedure}

Bronchoscopy was performed by one of six bronchoscopists with the subject in the supine position, through oral access and either with or without light conscious sedation according to the subjects' preference, with intravenous alfentanil $(0.25-1.0 \mathrm{mg})$. In addition to salbutamol administration related to the preceding spirometry, asthmatics received $5 \mathrm{mg}$ of nebulised salbutamol and in some cases also $0.5 \mathrm{mg}$ of ipratropium bromide (per judgement of the bronchoscopist). All participants received topical anaesthesia (lidocaine) by oral spray formulation $(10 \mathrm{mg} /$ dose $)$ prior to the procedure and through a catheter $(20 \mathrm{mg} / \mathrm{mL})$ in the bronchoscope's working channel during bronchoscopy. Additional alfentanil was administered during bronchoscopy, if deemed necessary. All participants received supplemental oxygen by nasal cannula, $3 \mathrm{~L} / \mathrm{min}$. The procedure included a general inspection, sampling with protective specimen brushes, bronchoalveolar lavage (BAL) of $50 \mathrm{~mL}+50 \mathrm{~mL}$ if $\mathrm{FEV}_{1}$ $>30 \%$ of predicted, small volume lavage $(20 \mathrm{~mL})$, and in one third of bronchoscopies; endobronchial biopsies. The biopsies, up to six in total, were taken from carinas in the right lower lobe after installation of $5 \mathrm{~mL}$ of $0.1 \%$ epinephrine. A disposable $1.8 \mathrm{~mm}$ cupped biopsy forceps was used. Subjects were monitored by three-lead ECG and pulse oximetry throughout the procedure. After bronchoscopy, the subjects were observed by trained nurses in our outpatient clinic for 2 hours. After discharge, the participants received a direct telephone number to the physician that performed their bronchoscopy in case of illness or worries following the procedure.

\section{Predictors and outcomes}

Information about subject-related explanatory variables was collected prior to bronchoscopy. All subjects were evaluated by the COPD Assessment Test (CAT),${ }^{12}$ utilised as a binary (CAT $\geq 10$ ) variable. COPD and asthma subjects reported the number of exacerbations in the preceding year. Partial oxygen pressure $\left(\mathrm{PaO}_{2}\right)$ at rest was measured. All subjects underwent spirometry after inhalation of $0.4 \mathrm{mg}$ salbutamol. Norwegian reference values for $\mathrm{FEV}_{1}$ and $\mathrm{FVC}$ were used. ${ }^{13}$ Subjects were categorised as ex-smokers, current-smokers or never-smokers. Subjects rated dread of the upcoming bronchoscopy on a scale from 0 to 10 , with 0 being 'not at all' and 10 being 'worst imaginable'. The six bronchoscopists were divided into a binary more-or-less experienced variable, based on experience level. The two most experienced bronchoscopists were all certified pulmonologists, senior consultants, and with more than 400 bronchoscopies, whereas the four least experienced failed to fulfil one or more of the above criteria.

Procedure-related explanatory variables included premedication with alfentanil and whether biopsies or BAL was performed.

Complications occurring during the procedure and observation period was recorded (online supplementary appendix 1). The main outcome was complications leading to unplanned intervention or premature termination of the procedure. An unplanned intervention was defined as any intervention that was not part of the prespecified bronchoscopy procedure, and deemed necessary by the bronchoscopist during or immediately after bronchoscopy. All supplementary administration of medications, included increased oxygen delivery, was regarded an unplanned intervention. Outcomes of special interest were observed cough, dyspnoea, decrease in oxygen saturation, haemodynamic changes (eg, pulse/blood pressure) and bleeding. To some degree these events are side-effects of the procedure, rather than complications. So, to be considered a complication, the event had to lead to an unplanned intervention. Examples of unplanned interventions included (but were not limited to) additional topical anaesthesia or sedation in the case of cough, increase in oxygen delivery in the case of desaturation, administration of (additional) epinephrine in the case of bleeding, bronchodilators in the case of dyspnoea, intravenous fluids and/or naloxone in the case of light-headedness or an observed reduction in blood pressure and antiemetics in the case of nausea. Severe complications are in this study limited to situations where a participant received urgent healthcare attendance due to a threat to life or health.

Self-reported events and discomfort were recorded in structured interviews that took place on-site after bronchoscopy, and by telephone 1 week after (online 
supplementary appendix 2). Discomfort was graded on a 10-point scale, where 0 represented 'no discomfort' and 10 'worst discomfort imaginable'. Participants were asked about willingness to repeat the procedure, and whether they had experienced fever sensation (temperature was not measured), dyspnoea, sputum, rhinitis, wheezing chest sounds, sore throat, cough, fatigue, haemoptysis and feeling of influenza (muscle/joint ache, fever, headache, malaise). Respiratory symptom exacerbations within the following week were defined according to modified Anthonisen criteria. ${ }^{14}$ All healthcare utilisations in the week following bronchoscopy (medication use, exacerbation treatment and hospitalisation) was recorded.

\section{Repeated bronchoscopies}

In a non-random selection, some participants were invited to undergo a repeated second, and in a few cases, third bronchoscopy. For each repeated bronchoscopy procedure, all information on the subject and the bronchoscopy procedure was recorded again.

\section{Statistics}

Bivariate analyses of explanatory and outcome variables in COPD and controls were performed using parametric (t-test, paired t-test) and non-parametric tests $\left(\chi^{2}\right.$, Fisher's exact test, Cohen's kappa, quantile regression). For subjects undergoing more than one bronchoscopy, the outcomes of the first and second bronchoscopy were compared. Data from asthma subjects were included in the regression models and in the overall descriptive statistics. However, comparison between asthmatics and the COPD and control groups was not performed due to the low number of asthmatics included. A logistic regression model for the dichotomous combined variable of unplanned intervention and/or premature termination of bronchoscopy and a quantile (median) regression model for the outcome of discomfort were fitted. In the multivariate regression models, age and sex were always included, with additional variables added based on bivariate effect size. Predictors were kept for the final model if $\mathrm{p}<0.1$ by a likelihood-ratio-test. Analyses were performed using R V.3.4.3 and V.3.6.1 and Stata V.14 for Windows and Stata V.15 for Mac.

\section{Patient and public involvement}

User involvement in the MicroCOPD study has been represented through informal contacts between our bronchoscopists/nurses and their patients, as well as regular meetings between the Department of Thoracic medicine and patient interest organisations such as The Norwegian Association of Heart and Lung Patients and The Norwegian Asthma and Allergy Association.

\section{RESULTS}

Five bronchoscopies were interrupted before bronchoscopic sampling started, and were excluded from further analyses. In one case, the cause of interruption was unreported. In four of these cases, interruption was due to a choking sensation when accessing the larynx and thereby difficult passage of the scope. Three out of these four subjects had received $0.5 \mathrm{mg}$ alfentanil. The eight participants from the pilot study and two volunteer co-workers were also excluded. The current analyses are thus based on 239 subjects (122 COPD, 16 asthma, 101 controls) undergoing bronchoscopy, of which 61 underwent two bronchoscopies and 11 underwent a third. Study design

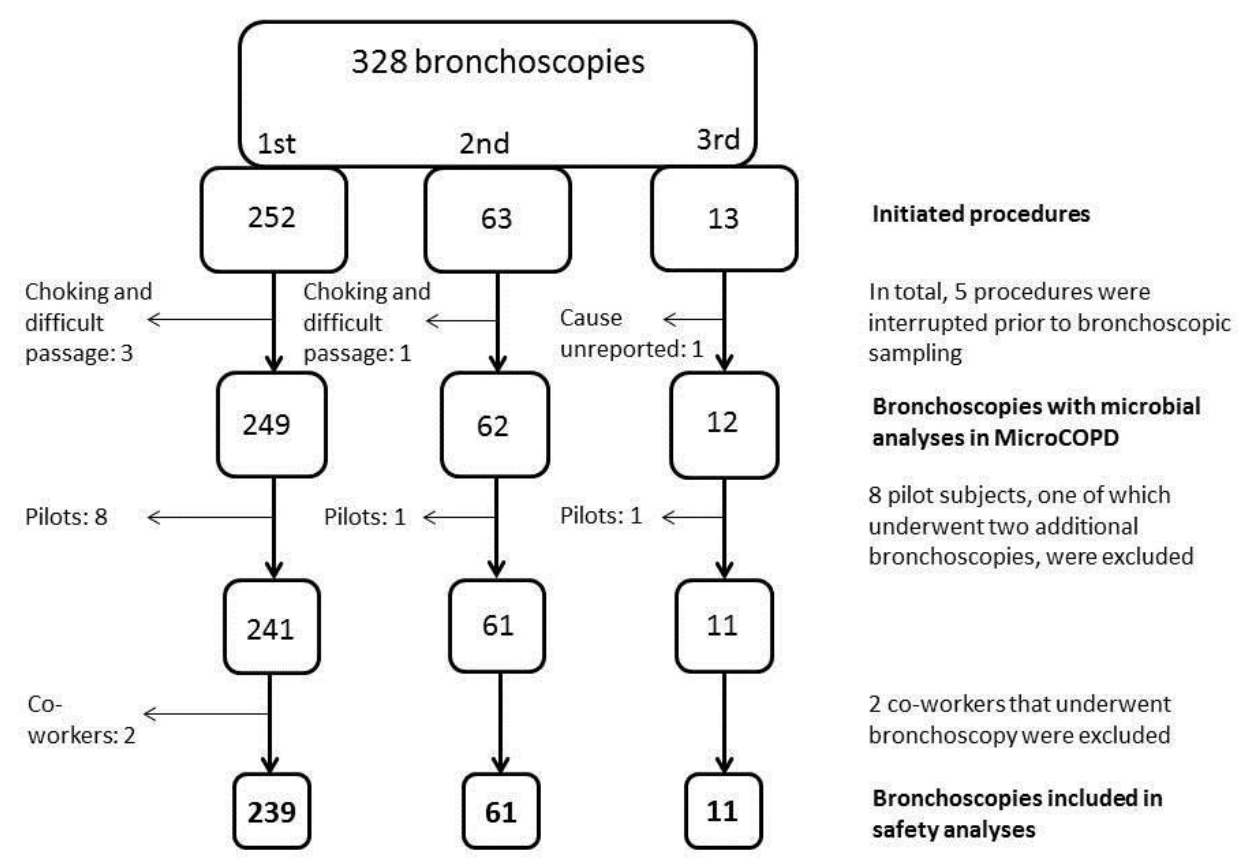

Figure 1 Study design. COPD, chronic obstructive pulmonary disease; MicroCOPD, Bergen COPD Microbiome Study. 
Table 1 Demographic and procedural characteristics in the different study groups

COPD $\stackrel{\text { Asthma }}{ } \stackrel{\text { Control }}{\begin{array}{l}\text { Comparison } \\ \text { between } \\ \text { COPD and } \\ \text { control }\end{array}}$
control

\begin{tabular}{lllll} 
Variable & $\mathbf{n}=\mathbf{1 2 2}$ & $\mathbf{n}=\mathbf{1 6}$ & $\mathbf{n}=\mathbf{1 0 1}$ & $\begin{array}{l}\text { group, two- } \\
\text { sided. }\end{array}$ \\
\hline Female sex & $44.3 \%$ & $56.3 \%$ & $42.6 \%$ & $\mathrm{p}=0.80$ \\
Age, years (SD) & $67.4(7.3)$ & $\begin{array}{l}65.5 \\
(12.6)\end{array}$ & $65.7(7.9)$ & $\mathrm{p}=0.11$ \\
$\begin{array}{l}\text { Body mass } \\
\text { index (SD) }\end{array}$ & $26.6(4.7)$ & $25.1(2.9)$ & $26.7(3.8)$ & $\mathrm{p}=0.81$
\end{tabular}

\begin{tabular}{|c|c|c|c|c|}
\hline Smoking status & & & & $\mathrm{p} \leq 0.01$ \\
\hline Daily & $23.8 \%$ & $0.0 \%$ & $24.8 \%$ & \\
\hline Ex-smokers & $75.4 \%$ & $75.0 \%$ & $58.4 \%$ & \\
\hline Never & $0.8 \%$ & $25.0 \%$ & $16.8 \%$ & \\
\hline $\begin{array}{l}\mathrm{FEV}_{1} / \mathrm{FVC} \text { ratio } \\
(\mathrm{SD})\end{array}$ & $0.46(0.13)$ & $\begin{array}{l}0.67 \\
(0.09)\end{array}$ & $0.74(0.05)$ & $\mathrm{p} \leq 0.01$ \\
\hline $\begin{array}{l}\mathrm{FEV}_{1} \% \text { of } \\
\text { predicted (SD) }\end{array}$ & $56.1(19.7)$ & $\begin{array}{l}90.7 \\
(13.3)\end{array}$ & $103.9(12.4)$ & $\mathrm{p} \leq 0.01$ \\
\hline
\end{tabular}

GOLD

\begin{tabular}{|c|c|c|c|c|}
\hline I & $8.2 \%$ & - & - & \\
\hline II & $50.8 \%$ & - & - & \\
\hline III & $24.6 \%$ & - & - & \\
\hline IV & $16.4 \%$ & - & - & \\
\hline CAT score $\geq 10$ & $79.5 \%$ & $68.8 \%$ & $26.7 \%$ & $p \leq 0.01$ \\
\hline $\mathrm{PaO}_{2}(\mathrm{SD})^{*}$ & $9.6(1.2)$ & $10.8(1.1)$ & $11.1(1.1)$ & $\mathrm{p} \leq 0.01$ \\
\hline $\mathrm{PaCO}_{2}(\mathrm{SD})^{\star}$ & $5.2(0.5)$ & $4.95(0.3)$ & $5.2(0.5)$ & $p=0.31$ \\
\hline $\begin{array}{l}\text { Exacerbation } \\
\geq 2 \text { prev. yeart }\end{array}$ & $17.2 \%$ & $6.25 \%$ & - & \\
\hline $\begin{array}{l}\text { Dread of } \\
\text { procedure }(\mathrm{SD}) \ddagger\end{array}$ & $4.0(2.8)$ & $3.5(2.4)$ & $3.3(2.6)$ & $p=0.07$ \\
\hline $\begin{array}{l}\text { Received } \\
\text { alfentanil } \\
\text { sedation }\end{array}$ & $90.2 \%$ & $100 \%$ & $83.2 \%$ & $p=0.122$ \\
\hline $\begin{array}{l}\text { Total lidocaine } \\
\text { dose, mg (SD) }\end{array}$ & $475(54)$ & $479(58)$ & $458(45)$ & $p=0.01$ \\
\hline BAL performed & $78.7 \%$ & $87.5 \%$ & $96.0 \%$ & $p \leq 0.01$ \\
\hline $\begin{array}{l}\text { Biopsies } \\
\text { performed }\end{array}$ & $39.3 \%$ & $87.5 \%$ & $37.6 \%$ & $p=0.79$ \\
\hline $\begin{array}{l}\text { Less } \\
\text { experienced } \\
\text { bronchoscopist }\end{array}$ & $63.1 \%$ & $43.8 \%$ & $59.4 \%$ & $p=0.57$ \\
\hline
\end{tabular}

Dread of procedure was rated on a $0-10$ scale, with 0 representing no dread and 10 worst dread.

*Three missing values (one control, two COPD).

†Five missing values (one COPD, four asthma).

$\ddagger 20$ missing values (11 COPD, eight controls, one asthma).

BAL, bronchoalveolar lavage; CAT, COPD assessment test; COPD, chronic obstructive pulmonary disease; $\mathrm{FEV}_{1}$, forced expiratory volume after 1 second; FVC, forced vital capacity; GOLD, Global Initiative for Chronic Lung Disease stage; $\mathrm{PaCO}_{2}$, partial pressure of carbon dioxide; $\mathrm{PaO}_{2}$, partial pressure of oxygen; prev, previous.

is shown in figure 1. Mean procedure duration was $14.2 \mathrm{~min}$ (SD 4.0). Subject and procedure characteristics at baseline are given in table 1 .

\section{First bronchoscopy; observed outcomes}

Periprocedural events requiring an unplanned intervention or early termination of bronchoscopy occurred in $25.9 \%$ of subjects. The majority of events were minor reactions, like cough, handled by alfentanil or lidocaine administration. No subject received more than $1.0 \mathrm{mg}$ alfentanil in total. Early termination occurred in 15 $(6.3 \%)$ of the procedures. The most frequent procedural events were cough, desaturation and bleeding (table 2). The seven bleeding events requiring an intervention resolved quickly after epinephrine administration. None required surgical intervention or transfusion.

Noted haemodynamic changes not requiring intervention were mainly elevations in heart rate and blood pressure during bronchoscopy. All but one haemodynamic change that led to intervention were decreases in BP that led to administration of either naloxone or intravenous fluids. The one increase in BP was accompanied by nausea, and antiemetic treatment was given.

Within the 2-hour observation period after bronchoscopy, the most common complications were dyspnoea $(\mathrm{n}=11)$ and sedation side effects (light-headedness, nausea) leading to intravenous naloxone or metoclopramide hydrochloride administration $(\mathrm{n}=10)$ (table 2). Only COPD subjects experienced dyspnoea requiring bronchodilators. For other observed immediate complications, there was no statistically significant difference between the two groups (table 2).

Three patients had potentially severe complications requiring immediate healthcare attendance: One COPD subject became unconscious 1 hour after the procedure and recovered after naloxone administration. One asthma subject syncopated during the first interview shortly after bronchoscopy, while still being monitored with ECG. At the time of syncopation, the monitor showed a bradycard rhythm, that was perceived as an asystole, and short cardiopulmonary resuscitation was initiated. The subject regained consciousness before respiration and rhythm/pulse was evaluated, and before administration of naloxone. Naloxone was provided shortly after. Both participants that syncopated had received $0.5 \mathrm{mg}$ of alfentanil as premedication. The procedures were uneventful, with no need of additional oxygen or medication. One asthma subject experienced bronchospasm at the end of an otherwise uneventful procedure and was treated with intravenous bronchodilators. The two asthma subjects were hospitalised for 24 hours. All recovered quickly without sequelae (table 2).

There were fewer unplanned interventions and/or premature terminations in subjects receiving alfentanil (OR 0.27, CI 0.11 to 0.66 ), and more in subjects with higher age (OR 1.73, CI 1.13 to 2.63) (figure 2). Subjects without alfentanil sedation did not receive different amounts of lidocaine during bronchoscopy $(\mathrm{p}=0.14)$. 
Table 2 Procedural complications of research bronchoscopy

\begin{tabular}{|c|c|c|c|c|}
\hline \multirow[b]{2}{*}{$\mathbf{N}$} & \multirow{2}{*}{$\begin{array}{l}\text { COPD } \\
122\end{array}$} & \multirow{2}{*}{$\frac{\text { Asthma }}{16}$} & \multirow{2}{*}{$\frac{\text { Controls }}{101}$} & \multirow{2}{*}{$\begin{array}{l}\text { Comparison, } \\
\text { COPD/controls }\end{array}$} \\
\hline & & & & \\
\hline \multicolumn{3}{|c|}{ Cough during bronchoscopy } & & $p=0.81$ \\
\hline $\begin{array}{l}\text { Without need } \\
\text { for intervention }\end{array}$ & $18.9 \%$ & $12.5 \%$ & $14.9 \%$ & \\
\hline $\begin{array}{l}\text { In need of } \\
\text { intervention }\end{array}$ & $4.1 \%$ & $6.3 \%$ & $5.9 \%$ & \\
\hline $\begin{array}{l}\text { Leading } \\
\text { to early } \\
\text { termination of } \\
\text { procedure }\end{array}$ & $2.5 \%$ & $6.3 \%$ & $3.0 \%$ & \\
\hline \multicolumn{3}{|c|}{ Bleeding during bronchoscopy } & & $p=0.06$ \\
\hline $\begin{array}{l}\text { Without need } \\
\text { for intervention }\end{array}$ & $9.0 \%$ & $12.5 \%$ & $4.0 \%$ & \\
\hline $\begin{array}{l}\text { In need of } \\
\text { intervention }\end{array}$ & $3.3 \%$ & $12.5 \%$ & $0.0 \%$ & \\
\hline $\begin{array}{l}\text { Leading } \\
\text { to early } \\
\text { termination of } \\
\text { procedure }\end{array}$ & $0.8 \%$ & $0.0 \%$ & $0.0 \%$ & \\
\hline \multicolumn{3}{|c|}{ Desaturation during bronchoscopy } & & $p=0.29$ \\
\hline $\begin{array}{l}\text { Without need } \\
\text { for intervention }\end{array}$ & $27.1 \%$ & $18.8 \%$ & $35.6 \%$ & \\
\hline $\begin{array}{l}\text { In need of } \\
\text { intervention }\end{array}$ & $4.1 \%$ & $6.3 \%$ & $1.0 \%$ & \\
\hline $\begin{array}{l}\text { Leading } \\
\text { to early } \\
\text { termination of } \\
\text { procedure }\end{array}$ & $0.0 \%$ & $0.0 \%$ & $1.0 \%$ & \\
\hline $\begin{array}{l}\text { Measurement } \\
\text { failure }\end{array}$ & $2.5 \%$ & $0.0 \%$ & $2.0 \%$ & \\
\hline \multicolumn{3}{|c|}{ Haemodynamic changes* } & & $p=0.38$ \\
\hline $\begin{array}{l}\text { Without need } \\
\text { for intervention }\end{array}$ & $15.6 \%$ & $12.5 \%$ & $9.9 \%$ & \\
\hline $\begin{array}{l}\text { In need of } \\
\text { intervention }\end{array}$ & $0.8 \%$ & $6.3 \%$ & $2.0 \%$ & \\
\hline $\begin{array}{l}\text { Leading } \\
\text { to early } \\
\text { termination of } \\
\text { procedure }\end{array}$ & $0.0 \%$ & $0.0 \%$ & $1.0 \%$ & \\
\hline $\begin{array}{l}\text { Measurement } \\
\text { failure }\end{array}$ & $0.8 \%$ & $0.0 \%$ & $0.0 \%$ & \\
\hline $\begin{array}{l}\text { Retching leading } \\
\text { to change of } \\
\text { bronchoscope } \\
\text { during } \\
\text { bronchoscopy }\end{array}$ & $0.0 \%$ & $0.0 \%$ & $1.0 \%$ & $p=0.45$ \\
\hline $\begin{array}{l}\text { Retching } \\
\text { leading to early } \\
\text { termination }\end{array}$ & $0.0 \%$ & $0.0 \%$ & $3.0 \%$ & $p=0.09$ \\
\hline $\begin{array}{l}\text { Panic, subject } \\
\text { unease }\end{array}$ & $1.6 \%$ & $0.0 \%$ & $0.0 \%$ & $p=0.50$ \\
\hline $\begin{array}{l}\text { Total amount of } \\
\text { early terminated } \\
\text { bronchoscopies, } \\
\text { all reasons. }\end{array}$ & $4.9 \%$ & $6.3 \%$ & $7.9 \%$ & $p=0.36$ \\
\hline
\end{tabular}

Continued

\begin{tabular}{|c|c|c|c|c|}
\hline \multirow[b]{2}{*}{$\mathbf{N}$} & \multirow{2}{*}{$\begin{array}{l}\text { COPD } \\
122\end{array}$} & \multirow{2}{*}{$\begin{array}{l}\text { Asthma } \\
16\end{array}$} & \multirow{2}{*}{$\frac{\text { Controls }}{101}$} & \multirow{2}{*}{$\begin{array}{l}\text { Comparison, } \\
\text { COPD/controls }\end{array}$} \\
\hline & & & & \\
\hline \multicolumn{5}{|c|}{$\begin{array}{l}\text { Potentially severe complications immediately } \\
\text { after bronchoscopy }\end{array}$} \\
\hline $\begin{array}{l}\text { Bronchospasm } \\
\text { immediately } \\
\text { after } \\
\text { bronchoscopy }\end{array}$ & $0.0 \%$ & $6.3 \%$ & $0.0 \%$ & \\
\hline $\begin{array}{l}\text { Syncope, } \\
\text { rescued by } \\
\text { naloxone }\end{array}$ & $0.8 \%$ & $0.0 \%$ & $0.0 \%$ & \\
\hline $\begin{array}{l}\text { Syncope, } \\
\text { started } \\
\text { resuscitation }\end{array}$ & $0.0 \%$ & $6.3 \%$ & $0.0 \%$ & \\
\hline \multicolumn{4}{|c|}{ Dyspnoea immediately after bronchoscopy } & $p<0.01$ \\
\hline $\begin{array}{l}\text { Without need } \\
\text { for intervention }\end{array}$ & $2.5 \%$ & $0.0 \%$ & $1.0 \%$ & \\
\hline $\begin{array}{l}\text { In need of } \\
\text { intervention }\end{array}$ & $8.2 \%$ & $6.3 \%$ & $0.0 \%$ & \\
\hline $\begin{array}{l}\text { Postprocedural } \\
\text { reactions } \\
\text { leading to use of } \\
\text { metoclopramide } \\
\text { hydrochloride } \\
\text { and/or naloxone }\end{array}$ & $3.3 \%$ & $6.3 \%$ & $5.0 \%$ & $p=0.74$ \\
\hline $\begin{array}{l}\text { Requiring any } \\
\text { intervention or } \\
\text { early termination } \\
\text { of bronchoscopy, } \\
\text { total }\end{array}$ & $26.2 \%$ & $37.5 \%$ & $23.8 \%$ & $p=0.67$ \\
\hline
\end{tabular}

*Not including complications listed under 'severe complications'. COPD, chronic obstructive pulmonary disease.

\section{First bronchoscopy; self-reported outcomes}

Sensation of fever was reported by $47.7 \%$ (table 3 ). There was no difference between those who had BAL performed and those who did not. COPD subjects reported more dyspnoea and increased wheezing sounds than the controls in the week following bronchoscopy. There was no difference between COPD and control subjects regarding other respiratory symptoms or exacerbation criteria (table 3 ).

Significant predictors of the 10-point discomfort scale were postprocedural fever, dread of bronchoscopy and being a never-smoker (table 4 ).

Seven COPD subjects $(5.7 \%)$ received antibiotic treatment or oral corticosteroids in the week following bronchoscopy, compared with one control subject (table 3 ).

One COPD subject had a suspected transient ischaemic attack 4 days after bronchoscopy. A magnetic resonance scan of the brain showed chronic circulatory disturbances. We classified this event as having an uncertain relation to the bronchoscopy.

Willingness to return for a research bronchoscopy was $79.8 \%$, and was not different between the COPD and control group (table 3). Among subjects unwilling to return, $87.2 \%$ would undergo bronchoscopy if recommended by a physician. 


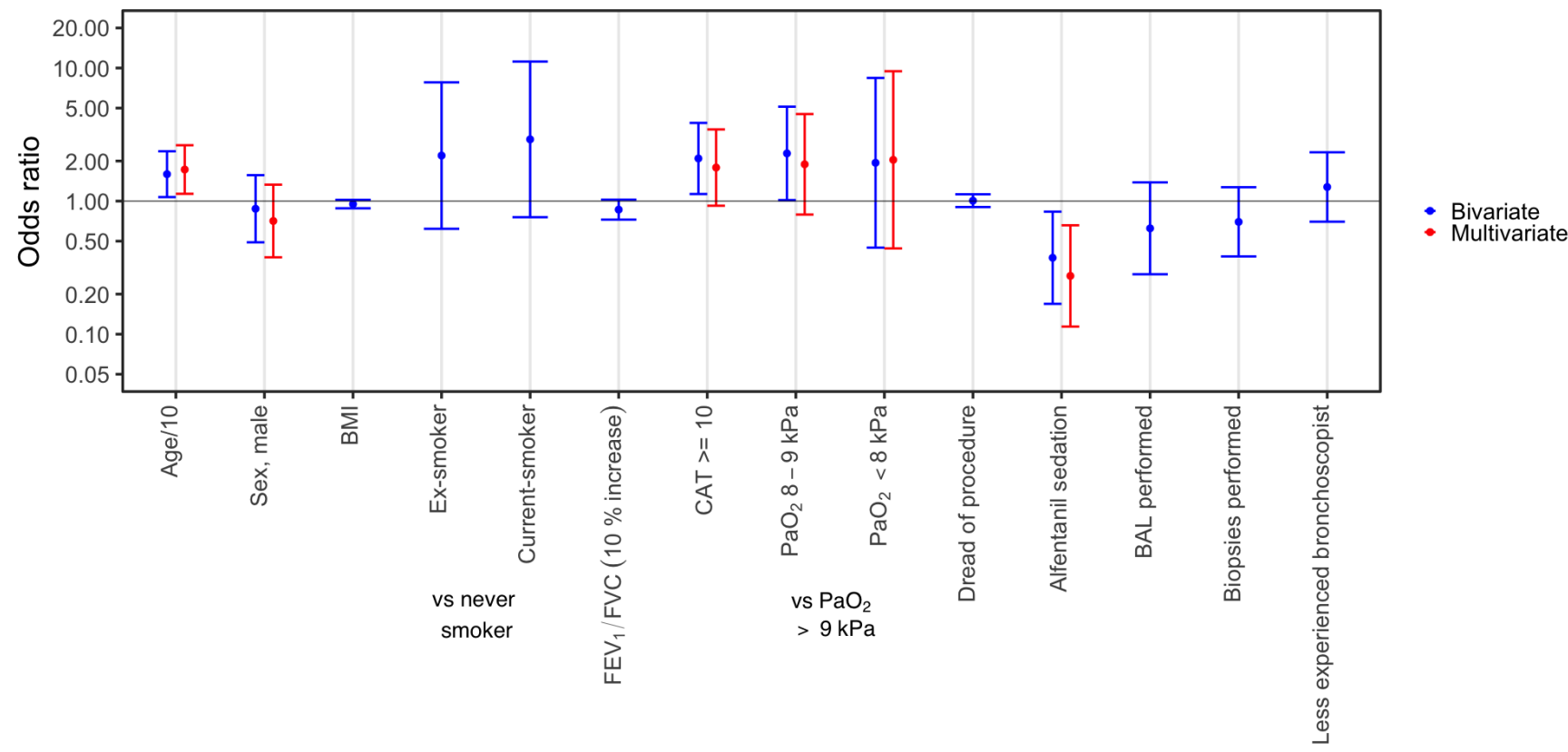

Figure 2 Logistic regression was used to evaluate the combined outcome of unplanned intervention or premature termination of bronchoscopy. Total number of observations in this model was 236 , as three observations were omitted due to missing values of oxygen. BAL, bronchoalveolar lavage; BMI, body mass index; CAT, COPD assessment test; COPD, chronic obstructive pulmonary disease; $\mathrm{FEV}_{1}$, forced expiratory volume in 1 second; $\mathrm{FVC}$, forced vital capacity; $\mathrm{PaO}_{2}$, partial oxygen pressure.

\section{Second bronchoscopy}

Among the 61 subjects who underwent a second bronchoscopy, the total complication rate of the first bronchoscopy was 20\%. Of those with a complicated first bronchoscopy, $42 \%$ had a complicated second bronchoscopy. In the group with no event in the first

\begin{tabular}{|c|c|c|c|c|}
\hline & \multirow{2}{*}{$\begin{array}{l}\text { COPD } \\
\mathrm{n}=122 \\
\end{array}$} & \multirow{2}{*}{$\begin{array}{l}\text { Asthma } \\
\mathrm{n}=16\end{array}$} & \multirow{2}{*}{$\begin{array}{l}\text { Controls } \\
\mathrm{n}=101\end{array}$} & \multirow{2}{*}{$\begin{array}{l}\text { Comparison, } \\
\text { COPD/controls }\end{array}$} \\
\hline & & & & \\
\hline Willingness to return for research bronchoscopy* & $76.2 \%$ & $68.8 \%$ & $84.2 \%$ & $\mathrm{p}=0.213$ \\
\hline Fever sensation $\dagger$ & $45.9 \%$ & $37.5 \%$ & $51.5 \%$ & $\mathrm{p}=0.440$ \\
\hline Increased dyspnoea† & $31.4 \%$ & $25.0 \%$ & $13.9 \%$ & $\mathrm{p}=0.002$ \\
\hline Increased sputum $\dagger$ & $26.2 \%$ & $25.0 \%$ & $22.8 \%$ & $\mathrm{p}=0.540$ \\
\hline Change in sputum colourt & $20.7 \%$ & $25.0 \%$ & $12.9 \%$ & $\mathrm{p}=0.125$ \\
\hline Increased rhinitis $\dagger$ & $31.4 \%$ & $25.0 \%$ & $31.7 \%$ & $\mathrm{p}=0.965$ \\
\hline Increased wheezing respiration $\dagger$ & $24.8 \%$ & $12.5 \%$ & $7.9 \%$ & $p=0.001$ \\
\hline Sore throat or coughing $\dagger$ & $54.1 \%$ & $56.3 \%$ & $57.4 \%$ & $p=0.601$ \\
\hline Increased astheniał & $37.2 \%$ & $31.3 \%$ & $27.0 \%$ & $p=0.108$ \\
\hline $\begin{array}{l}\text { Flu-like symptoms, including fever, muscle/joint pain, headache, } \\
\text { reduced general condition* }\end{array}$ & $41.7 \%$ & $31.3 \%$ & $50.5 \%$ & $\mathrm{p}=0.189$ \\
\hline Discomfort graded from 0 to 10 . Mean (SD) ${ }^{\star}$ & $4.2(2.6)$ & $3.8(2.8)$ & $4.2(1.9)$ & $\mathrm{p}=0.364$ \\
\hline Exacerbation criteria fulfilled, totalł & $45.5 \%$ & $37.5 \%$ & $33.0 \%$ & $p=0.169$ \\
\hline Hospitalisation related to bronchoscopy§ & $0.8 \%$ & $12.5 \%$ & $1.0 \%$ & $p=1.000$ \\
\hline Received treatment as if exacerbation (prednisolone/antibiotics)§ & $5.7 \%$ & $0.0 \%$ & $1.0 \%$ & $\mathrm{p}=0.076$ \\
\hline
\end{tabular}

*Two missing values (two COPD).

†One missing value (one COPD),

‡Two missing values (one COPD, one control).

§One missing value (one control).

COPD, chronic obstructive pulmonary disease. 
bronchoscopy, 12\% had a complicated second bronchoscopy $(\mathrm{p}=0.01)$.

Especially sensation of fever after the first bronchoscopy was associated with similar reports after a second bronchoscopy $(\mathrm{p}<0.01)$. Among subjects undergoing a second bronchoscopy, $45 \%$ reported fever after the first bronchoscopy. Of these, $63 \%$ experienced fever after the second bronchoscopy. Of those who did not report fever in their first bronchoscopy, only $27 \%$ reported fever after the second procedure.

\section{DISCUSSION}

In our single-centre bronchoscopy study we found that only $1.3 \%$ of 239 participants experienced serious complications, all of whom had a diagnosis of COPD or asthma. No complication had long-term consequences. Of first bronchoscopies, $6.3 \%$ were prematurely terminated.
As it can be unclear what constitutes a complication or an expected discomfort, we chose to define a complication as an observed event that led to an unplanned intervention, and we chose to let subjects report overall discomfort during the week after the procedure. The most frequent complications were cough, dyspnoea and other discomforts leading to administration of naloxone or metoclopramide hydrochloride. The most common discomforts reported after 1 week were sore throat, fever and flu-like symptoms.

Although one fourth of the subjects required some form of unplanned intervention, it is important to point out that our definition of unplanned intervention was made quite wide to capture as many events as may be of any significance. However, many events will regularly happen during a routine bronchoscopy, like cough or light bleeding, being routinely handled by extra

Table 4 Predictors of perceived discomfort during and after bronchoscopy, estimated from a quantile regression analysis

\begin{tabular}{|c|c|c|c|c|c|}
\hline \multirow[b]{2}{*}{ Variable } & \multirow[b]{2}{*}{ Coef. } & \multicolumn{2}{|l|}{ Cls } & \multirow[b]{2}{*}{ Type* } & \multirow[b]{2}{*}{$P$ value } \\
\hline & & Lower & Upper & & \\
\hline Sex, male & -1 & -1.91 & -0.08 & Bivariate & 0.03 \\
\hline Age/10 & -0.60 & -1.11 & -0.09 & Bivariate & 0.22 \\
\hline Body mass index & 0 & -0.10 & 0.10 & Bivariate & 1.00 \\
\hline \multicolumn{6}{|l|}{ Smoking status } \\
\hline Ex-smoker & 0 & -2.06 & 2.06 & Bivariate & 1.00 \\
\hline Current smoker & 0 & -2.37 & 2.37 & Bivariate & 1.00 \\
\hline $\mathrm{FEV}_{1} / \mathrm{FVC}$ & 0 & -0.03 & 0.03 & Bivariate & 1.00 \\
\hline CAT score $\geq 10$ & 1.5 & 0.48 & 2.52 & Bivariate & $<0.01$ \\
\hline \multicolumn{6}{|l|}{$\mathrm{PaO}_{2}$} \\
\hline $\mathrm{PaO}_{2} 8-9 \mathrm{kPa}$ & 0 & -1.79 & 1.79 & Bivariate & 1.00 \\
\hline $\mathrm{PaO}_{2}<8 \mathrm{kPa}$ & 1 & -3.42 & 5.42 & Bivariate & 0.66 \\
\hline Dread of procedure & 0.34 & 0.16 & 0.50 & Bivariate & $<0.01$ \\
\hline Alfentanil sedation & 0 & -1.28 & 1.28 & Bivariate & 1.00 \\
\hline BAL performed & 0 & -1.74 & 1.74 & Bivariate & 1.00 \\
\hline Biopsies performed & 0 & -0.91 & 0.91 & Bivariate & 1.00 \\
\hline Less experienced bronchoscopist & 1 & -0.09 & 2.09 & Bivariate & 0.07 \\
\hline Fever sensation & 1.5 & 0.28 & 2.72 & Bivariate & 0.02 \\
\hline Complication & 0.5 & 0.83 & 1.83 & Bivariate & 0.46 \\
\hline Sex, male & -0.08 & -0.88 & 0.73 & Multivariate & 0.83 \\
\hline Age/10 & -0.36 & -0.84 & 0.11 & Multivariate & 0.14 \\
\hline CAT score $\geq 10$ & 0.62 & -0.17 & 1.41 & Multivariate & 0.12 \\
\hline Fever & 0.87 & 0.09 & 1.65 & Multivariate & 0.03 \\
\hline Dread of procedure & 0.30 & 0.16 & 0.44 & Multivariate & $<0.01$ \\
\hline \multicolumn{6}{|l|}{ Smoking status } \\
\hline Ex-smoker & -1.35 & -2.34 & -0.35 & Multivariate & 0.01 \\
\hline Current smoker & -2.05 & -3.38 & -0.67 & Multivariate & $<0.01$ \\
\hline
\end{tabular}

Discomfort was rated on a $0-10$ scale, with 0 representing no discomfort and 10 worst imaginable discomfort.

*In the multivariate model, age and sex were included and additional variables were added based on bivariate effect size. Predictors were kept for the final model if $\mathrm{p}<0.1$ by a likelihood-ratio-test.

BAL, bronchoalveolar lavage; CAT, COPD assessment test; Coef, Coefficient; FEV ${ }_{1}$, forced expiratory volume after 1 second; FVC, forced vital capacity; $\mathrm{PaO}_{2}$, partial pressure of oxygen. 
medication without any harm to the person undergoing the procedure.

The only statistically significant difference between COPD subjects and controls was more postprocedural dyspnoea in COPD subjects. These findings are in accordance with a recent study that reported similar safety profiles in patients with and without $\mathrm{COPD},{ }^{15}$ and previous findings of more respiratory complications in COPD patients following bronchoscopy. ${ }^{16}$ Predictors of unplanned intervention or early procedure termination were lack of sedation and higher age. Predictors of reported discomfort were smoking habits, dread of bronchoscopy and postprocedural fever, but effect sizes were small. The reason why ever smokers reported less discomfort is unknown, but one possibility is a higher tolerance for respiratory symptoms.

Aside from more dyspnoea, bronchoscopy of COPD patients was not associated with more complications, even when $\mathrm{FEV}_{1}$ was below $30 \%$ of predicted. However, we did not perform BAL in subjects with the most reduced $\mathrm{FEV}_{1}$. Less dyspnoea in the asthma group than in the COPD group could be explained by a low number of asthma patients, but also by preprocedural bronchodilation. The British Thoracic Society guideline for diagnostic flexible bronchoscopy in adults states that nebulised bronchodilators should be considered before bronchoscopy in patients with asthma, ${ }^{17}$ whereas no benefit of inhaled salbutamol has been identified in COPD patients. ${ }^{18}$

The low number of asthma subjects makes it impossible to draw conclusions based on complication rates in the asthma group. That the two subjects who were hospitalised directly following bronchoscopy both had asthma could indicate that subjects with asthma are more prone to complications.

Alfentanil reduced overall need for unplanned intervention or early termination of bronchoscopy, even though ten cases of drug-induced complications were included in the analyses. There is no commonly accepted best practice regarding choice of sedative agent for bronchoscopy. ${ }^{19}$ Bronchoscopy sedation with alfentanil has only recently been compared with placebo or dexmedetomidine in a relatively small randomised controlled trial. The authors reported more events of hypoxaemia and heart rate changes in the alfentanil group, but present few clinically significant differences between the groups. ${ }^{20}$ Older studies comparing alfentanil and midazolam sedation have shown that alfentanil sedation results in less cough, but not necessarily less discomfort or improved ease of the procedure. ${ }^{2122}$ The trial comparing alfentanil to placebo did not find a statistically significant difference in cough, and did not address subject discomfort. ${ }^{20}$ Sedation was not randomised in our study, but offered to all. We were unable to find differences in reported discomfort in subjects with and without sedation. A non-recorded observation was that some participants declined sedation to be able to drive a motor vehicle after bronchoscopy. Midazolam is not routinely used at our institution, although sometimes preferred in patients with manifest anxiety for instance. Patients receiving midazolam may relax more, which may have preferable effects, however we cannot assess what impact midazolam may have on procedural discomfort from the current study.

Thus, alfentanil appears to provide clear benefits for the majority of recipients, but does come with the risk of serious events, especially related to depression of respiration. Using a standardised sedation protocol and having an experienced team performing the bronchoscopies is likely beneficial in maximising benefit and minimising risk.

The postbronchoscopy fever rate was in accordance with a paediatric study. ${ }^{23}$ Others have reported lower rates $(0 \%-38 \%){ }^{24-30}$ The causes of this wide range in rates are unclear, but the studies vary greatly in patient population and design. A possible reason for our relatively high fever rate is that we asked for a self-reported fever, which also included a 'fever sensation' instead of measuring body temperature. The abovementioned paediatric study found more fever in cases where BAL had been performed. In the current study, fever was not associated with BAL. However, BAL was not done in a randomised manner, and was not performed in patients with very severe obstruction.

Postbronchoscopy fever itself is harmless, but is associated with subject discomfort. COPD patients may interpret fever sensation as an early sign of exacerbations. Although subjects reported relatively high scores of discomfort and many had airway exacerbation symptoms, $79.8 \%$ would undergo research bronchoscopy again. Our findings on willingness to return fall within the range of previously reported rates, ${ }^{15}$ 31-34 but might be influenced by response bias.

Of participants undergoing a second bronchoscopy, the first bronchoscopy appears to be predictive for both immediate complications and fever. This indicates that the fever is at least partially subject-related and not procedural-related. To the best of our knowledge, there are no other studies on the complication or discomfort rate in repeated bronchoscopies.

Our analyses suggest that exacerbation symptoms may increase after bronchoscopy. Thus, patients might profit from an increase in their bronchodilators or inhaled steroids before and after the procedure. Dread of bronchoscopy before the procedure predicted discomfort, suggesting an anxiety relieving effect of information. Knowledge about factors influencing discomfort may help bronchoscopists improve their preprocedural information.

There are reasons why caution should be used when comparing our results to the clinical bronchoscopy setting. First, the patients undergoing bronchoscopy may be healthier than patients undergoing bronchoscopy for a clinical indication. Despite setting no upper age-limit (the oldest individual was 82 years old) and including COPD GOLD stage 4, the frailest subjects were excluded. Second, clinical bronchoscopies often have longer 
durations and include more invasive techniques than those applied and accepted in our research setting. Diagnostic bronchoscopies investigating potential malignant disease obtains larger and often transbronchial biopsies. Therapeutic bronchoscopies, such as endobronchial coil therapy, is associated with more severe complications (eg, pneumothorax and death).$^{35}$ Third, volunteers are possibly more positive towards the procedure than patients in a clinical setting. This could cause them to have an overall more positive experience, resulting in less perceived discomfort. However, they could also report more complications as a result of a greater discrepancy between what they expected and the actual procedure. Fourth, the procedure was standardised. Hence, the bronchoscopist had to make fewer decisions during bronchoscopy, which may lower complication rates of research bronchoscopy.

This descriptive study has some limitations. For many of our descriptive and outcome variables, we used selfreported outcomes. Recording of complications such as dyspnoea, cough, or bleeding will by nature be subjective. Therefore, we reported events that had a consequence in the form of intervention or termination. The perceived need to intervene is however also subjective and at the discretion of each bronchoscopist. Importantly, we did not observe differences in complication or discomfort rates between the bronchoscopists in our study. All subjects were monitored with ECG, pulse oximeter and blood pressure measurements, however these parameters were only noted in the case of an observed event. If these measurements had been systematically collected, they could have been implemented in quality control or further analyses. This could have improved the study and potentially aided in defining cutoffs for future investigations.

\section{CONCLUSION}

Only $1.3 \%$ of subjects had a potentially serious complication, all of whom had no sequela, indicating that bronchoscopy applying invasive techniques such as BAL and mucosal biopsies is a safe procedure in studies of patients with obstructive lung disease. Overall, a sizeable number of subjects perceived some discomfort or less serious complications, but these were minor and to a large degree to be expected from the procedure. Sore throat, fever and flu-like symptoms each occurred in roughly half of all subjects. Non-sedation and higher age were significantly associated with more unplanned interventions during bronchoscopy, indicating that sedation improves tolerability of the procedure and is advised. Information regarding expected discomfort should be given prior to bronchoscopy.

Acknowledgements The authors wish to thank Kristina Apalseth, Marit Aardal, Hildegunn Bakke Fleten, Lise Østgård Monsen, Ane Aamli Gagnat and Ingvild Haaland for their contributions in the data collection, and Marianne Aanerud and Øystein Fløtten for constructive criticism of the manuscript.
Contributors EOL had full access to all of the data in the study and takes responsibility for the integrity of the data and the accuracy of the data analysis. EOL, TMLE, EMHM, EN, GRH, KSK, SL, ØS and RN participated in different aspects of data collection. TMLE, GRH, KSK, SL, ØS and RN performed the bronchoscopies. EOL, TMLE, EMHM, EN, GRH, KSK, SL, ØS, PSB and RN contributed substantially to the study design, data analysis and interpretation, and the writing of the manuscript.

Funding The MicroCOPD study was funded by unrestricted grants and fellowships from Helse Vest, Bergen Medical Research Foundation, the Endowment of Timber Merchant A. Delphin and Wife through the Norwegian Medical Association and GlaxoSmithKline through the Norwegian Respiratory Society.

Competing interests EOL, EMHM, EN, KSK, ØS and PSB declare no competing interests. TMLE has for the last three years received lecture fees from Boehringer Ingelheim, Roche and Astra Zeneca. GRH has for the last three years received lecture fees from Novartis and Boehringer Ingelheim. RN reports grants from GlaxoSmithKline, during the conduct of the study; grants from Boehringer Ingelheim, grants and personal fees from AstraZeneca, grants from Novartis, personal fees from GlaxoSmithKline, outside the submitted work. SL has for the last three years received lecture fees from Philips, Novartis and Astra Zeneca, and advisory board fees (paid to employer) from Novartis and Astra Zeneca, all outside the submitted work.

Patient consent for publication Not required.

Ethics approval The Regional Committee for Medical and Health Research Ethics approved the project (REK VEST 2011/1307). All participants provided written informed consent.

Provenance and peer review Not commissioned; externally peer reviewed.

Data availability statement The data and command lines necessary for running the analyses presented in this article are available upon reasonable request.

Open access This is an open access article distributed in accordance with the Creative Commons Attribution Non Commercial (CC BY-NC 4.0) license, which permits others to distribute, remix, adapt, build upon this work non-commercially, and license their derivative works on different terms, provided the original work is properly cited, appropriate credit is given, any changes made indicated, and the use is non-commercial. See: http://creativecommons.org/licenses/by-nc/4.0/.

ORCID iD

Elise Orvedal Leiten http://orcid.org/0000-0002-5588-9076

\section{REFERENCES}

1 Grendelmeier P, Kurer G, Pflimlin E, et al. Feasibility and safety of propofol sedation in flexible bronchoscopy. Swiss Med Wkly 2011;141:w13248.

2 Carr IM, Koegelenberg CFN, von Groote-Bidlingmaier F, et al. Blood loss during flexible bronchoscopy: a prospective observational study. Respiration 2012;84:312-8.

3 Rosell A, Xaubet A, Agustí C, et al. A new BAL fluid instillation and aspiration technique: a multicenter randomized study. Respir Med 2006;100:529-35.

4 Gibson PG, Breit SN, Bryant DH. Hypoxia during bronchoalveolar lavage. Aust N Z J Med 1990;20:39-43.

5 Ogawa T, Imaizumi K, Hashimoto I, et al. Prospective analysis of efficacy and safety of an individualized-midazolam-dosing protoco for sedation during prolonged bronchoscopy. Respir Investig 2014;52:153-9.

6 Meduri GU, Stover DE, Greeno RA, et al. Bilateral bronchoalveolar lavage in the diagnosis of opportunistic pulmonary infections. Chest 1991;100:1272-6.

7 Leiten EO, Martinsen EMH, Bakke PS, et al. Complications and discomfort of bronchoscopy: a systematic review. Eur Clin Respir J 2016;3:33324.

8 Grønseth R, Haaland I, Wiker HG, et al. The Bergen COPD microbiome study (MicroCOPD): rationale, design, and initial experiences. Eur Clin Respir J2014:1.

9 Eagan TML, Ueland T, Wagner PD, et al. Systemic inflammatory markers in COPD: results from the Bergen COPD cohort study. Eur Respir J 2010;35:540-8.

10 Sørheim I-C, Johannessen A, Grydeland TB, et al. Case-Control studies on risk factors for chronic obstructive pulmonary disease: how does the sampling of the cases and controls affect the results? Clin Respir J 2010;4:89-96.

11 The HMW. 2017 global initiative for chronic obstructive lung disease report and practice implications for the respiratory therapist.. Respir Care 2017;62:1492-500. 
12 Jones PW, Harding G, Berry P, et al. Development and first validation of the COPD assessment test. Eur Respir J 2009;34:648-54.

13 Johannessen A, Lehmann S, Omenaas ER, et al. PostBronchodilator spirometry reference values in adults and implications for disease management. Am J Respir Crit Care Med 2006;173:1316-25.

14 Anthonisen NRet al. Antibiotic therapy in exacerbations of chronic obstructive pulmonary disease. Ann Intern Med 1987;106:196-204.

15 Grendelmeier P, Tamm M, Jahn K, et al. Flexible bronchoscopy with moderate sedation in COPD: a case-control study. Int $J$ Chron Obstruct Pulmon Dis 2017;12:177-87.

16 Bellinger CR, Khan I, Chatterjee AB, et al. Bronchoscopy safety in patients with chronic obstructive lung disease. J Bronchology Interv Pulmonol 2017;24:98-103.

17 Du Rand IA, Blaikley J, Booton R, et al. British thoracic Society guideline for diagnostic flexible bronchoscopy in adults: accredited by NICE. Thorax 2013;68:11-44.

18 Stolz D, Pollak V, Chhajed PN, et al. A randomized, placebocontrolled trial of bronchodilators for bronchoscopy in patients with COPD. Chest 2007;131:765-72.

19 José RJ, Shaefi S, Navani N. Sedation for flexible bronchoscopy: current and emerging evidence. Eur Respir Rev 2013;22:106-16.

20 Riachy M, Khayat G, Ibrahim I, et al. A randomized double-blind controlled trial comparing three sedation regimens during flexible bronchoscopy: dexmedetomidine, alfentanil and lidocaine. Clin Respir J 2018;12:1407-15.

21 Greig JH, Cooper SM, Kasimbazi HJN, et al. Sedation for fibre optic bronchoscopy. Respir Med 1995;89:53-6.

22 Houghton CM, Raghuram A, Sullivan PJ, et al. Pre-medication for bronchoscopy: a randomised double blind trial comparing alfentanil with midazolam. Respir Med 2004;98:1102-7.

23 Picard E, Schwartz S, Goldberg S, et al. A prospective study of fever and bacteremia after flexible fiberoptic bronchoscopy in children. Chest 2000;117:573-7.
24 Hemmers T, Nüßlein T, Teig N, et al. Prospective study of fever after bronchoalveolar lavage in children. Klin Padiatr 2006;218:74-8.

25 Mohallem Fonseca MT, Camargos PAM, Abou Taam R, et al. Incidence rate and factors related to post-bronchoalveolar lavage fever in children. Respiration 2007;74:653-8.

26 Schellhase DE, Tamez JR, Menendez AA, et al. High fever after flexible bronchoscopy and bronchoalveolar lavage in noncritically ill immunocompetent children. Pediatr Pulmonol 1999;28:139-44.

27 Georgiades G, Myrianthefs P, Venetsanou K, et al. Temperature and serum proinflammatory cytokine changes in patients with NSCLC after BAL. Lung 2003;181:35-47.

28 Kane RC, Cohen MH, Fossieck BE, et al. Absence of bacteremia after fiberoptic bronchoscopy. Am Rev Respir Dis 1975;111:102-4.

29 Strumpf IJ, Feld MK, Cornelius MJ, et al. Safety of fiberoptic bronchoalveolar lavage in evaluation of interstitial lung disease. Chest 1981;80:268-71.

30 Kanemoto K, Satoh $\mathrm{H}$, Ishikawa $\mathrm{H}$, et al. Prospective study of fever and pneumonia after flexible fiberoptic bronchoscopy in older people. J Am Geriatr Soc 2006;54:827-30.

31 Hehn BT, Haponik E, Rubin HR, et al. The relationship between age and process of care and patient tolerance of bronchoscopy. J Am Geriatr Soc 2003;51:917-22.

32 Hirose $\mathrm{T}$, Okuda $\mathrm{K}$, Ishida $\mathrm{H}$, et al. Patient satisfaction with sedation for flexible bronchoscopy. Respirology 2008;13:722-7.

33 Lechtzin N, Rubin HR, White P, et al. Patient satisfaction with bronchoscopy. Am J Respir Crit Care Med 2002;166:1326-31.

34 YL N, YL L, Lin TY, et al. Conscious sedation reduces patient discomfort and improves satisfaction in flexible bronchoscopy. Chang Gung Med J 2010;33:443-52.

35 Sciurba FC, Criner GJ, Strange C, et al. Effect of endobronchial coils vs usual care on exercise tolerance in patients with severe emphysema: the RENEW randomized clinical trial. JAMA 2016;315:2178-89. 